\title{
Arquivo Fotográfico Aristides Azevedo Pacheco Leão
}

\section{Aristides Azevedo Pacheco Leão's Photographic Archive}

\author{
Ivanita Raquel Barbosa Velloso \\ Assessora do Projeto Memória \\ Telma Bonniau Gitirana \\ Pesquisadora do Projeto Memória \\ Rua Araújo Porto Alegre, 64/5a andar \\ 20030-060 Rio de Janeiro - RJ Brasil \\ abc@abc.org.br
}

$\mathrm{O}$ Projeto Memória da Academia Brasileira de Ciências (ABC) desde a sua criação, em 1995, tem como um de seus objetivos principais recuperar e divulgar a história da ciência no Brasil, utilizando-se dos documentos concernentes à instituição e seus acadêmicos.

Ao tomar conhecimento de que as imagens fotográficas do cientista Aristides Azevedo Pacheco Leão estavam à espera de tratamento técnico adequado, a equipe não se furtou de dar sentido a esse conjunto valioso de imagens. Assim, esse foi o primeiro arquivo fotográfico de um acadêmico organizado pelo Projeto Memória.

A organização do arquivo fotográfico permitiu-nos visualizar a trajetória de seu titular pelas instituições que o notabilizaram como grande cientista, e também recordar instantes de seu mundo privado: imagens da época de Harvard (EUA), quando foi fotografado ao lado do primeiro eletroencefalógrafo; fotografias de seu primeiro laboratório na Faculdade Nacional de Medicina; instantâneos das viagens científicas e expedições pelo interior do Brasil; registros das solenidades nas quais participou como representante da academia; homenagens e prêmios recebidos ao longo de sua carreira, convivência com amigos e familiares.

\section{O nosso retratado...}

O nome de Aristides Azevedo Pacheco Leão (1914-93) merece destaque na história da ABC. Ingressou como membro associado em 1948, sendo promovido a membro titular em 1951, na Seção de Ciências Biológicas. Atuou como vice-presidente nos períodos de 1955-57 e 1965-67, presidente em exercício de maio de 1966 a maio de 1967 e presidente durante sete biênios consecutivos (1967-81). Em 20 de dezembro de 1993, Aristides foi eleito presidente emérito em homenagem póstuma. No ano seguinte, a academia prestou-lhe mais 
duas grandes homenagens, dando à sua biblioteca e ao Programa de Estímulo a Vocações Científicas o nome de Aristides Pacheco Leão.

Concluiu sua formação acadêmica em ciências biomédicas na Universidade de Harvard, em Cambridge, obtendo doutorado em fisiologia no ano de 1943. A tese 'Spreading depression of eletrical activity in the cerebral cortex', publicada em 1944, no Journal of Neurophysiology, tornou-o fenômeno conhecido internacionalmente como Leão's spreading depression.

Embora tenha alcançado o reconhecimento de seus pares e, por isso, tenha sido convidado a permanecer nos Estados Unidos, Aristides retornou ao Rio de Janeiro. Aqui, instalou-se no Instituto de Biofísica da Universidade do Brasil, atualmente Instituto de Biofísica Carlos Chagas Filho da Universidade Federal do Rio de Janeiro (UFRJ), contribuindo decisivamente no desenvolvimento da ciência nacional.

A par da sua consagrada carreira na área de neurociências, teve grande interesse nas pesquisas em ciências naturais: botânica e zoologia, com destaque em ornitologia. É sabido que suas investigações neste campo ganharam repercussão no meio acadêmico.

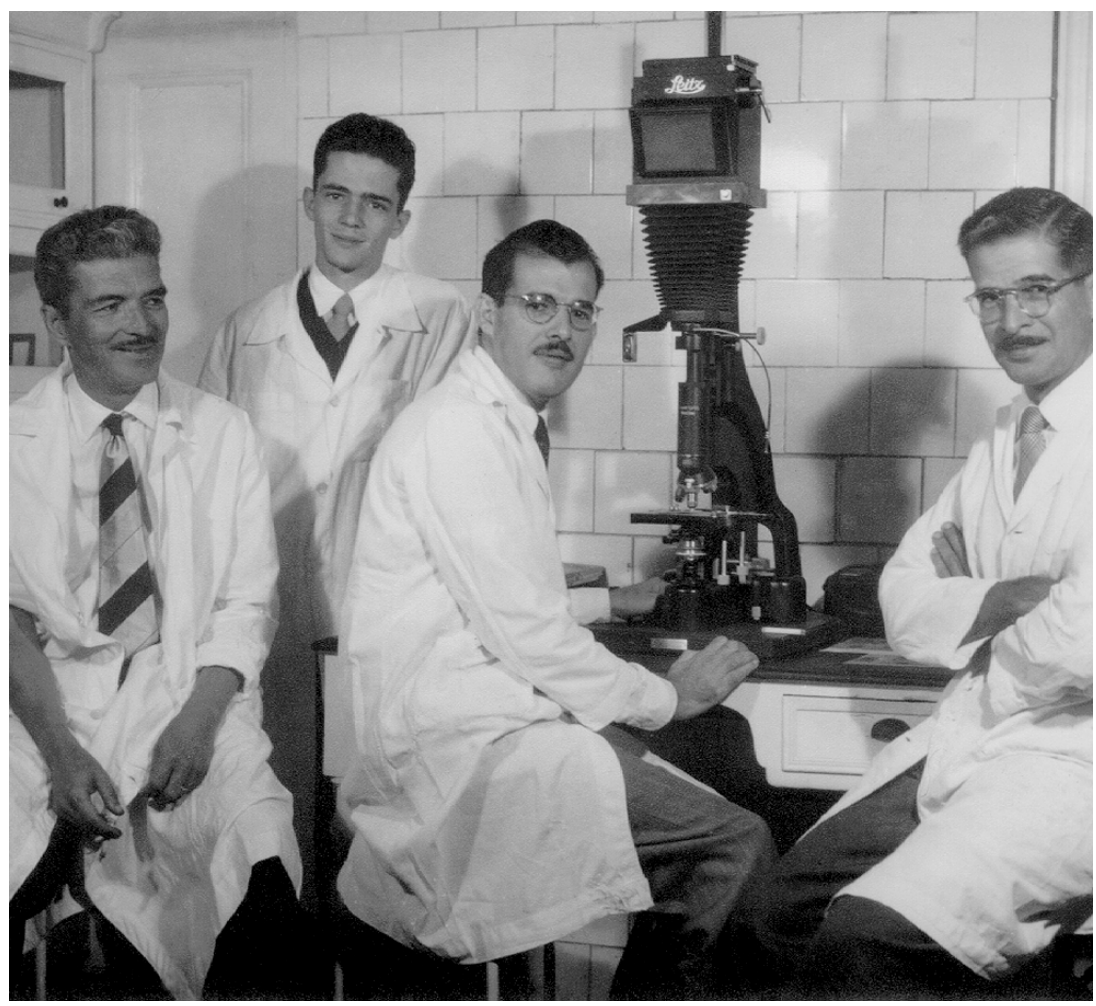

Aristides Azevedo Pacheco Leão e outros pesquisadores no Laboratório de Biofísica da Faculdade $\mathcal{N a c i o n a l}$ de Medicina da Universidade do Brasil (Praia Vermelha), na década de 1940. Da esquerda para a direita: Gustavo de Oliveira Castro, Gustavo de Oliveira Castro Filho, Antonio Moreira Couceiro e Aristides Azevedo Pacheco Leão. 


\section{objetos da memória}

Os objetos da memória de Aristides Azevedo Pacheco Leão estão no Rio de Janeiro, sob a guarda da família, que manteve o espírito cuidadoso de seu titular. Ao lado de manuscritos, mapas, livros e instrumentos utilizados em suas pesquisas de campo, encontram-se imagens fotográficas que retratam sua trajetória científica, viagens, hábitos e amizades.

O contato com a documentação fotográfica levou-nos à convivência com a viúva, sra. Elisabeth Pacheco Leão - Bebeth, como ele a chamava -, no intuito de rememorar os fatos e identificar as imagens que revelaram a trajetória singular do homem e do cientista.

Demais contemporâneos de Aristides, com atuação destacada junto a diversas instituições científicas, foram também fontes de consulta. Durante as entrevistas compartilhamos recordações, que nos ajudaram a compor um perfil de Aristides Azevedo Pacheco Leão.

Particularidades de seu cotidiano e de seu trabalho científico se confundiram nos relatos. Pesquisador exigente e cuidadoso, Aristides Azevedo Pacheco Leão vivia o seu dia a dia com o zelo e o perfeccionismo de um investigador da ciência. Dono de notória erudição e modéstia, surpreendia a quem dele se aproximasse pela primeira vez, por saber conjugar, com perfeição, receptividade e conhecimento. Amante das viagens, debruçava-se sobre mapas e anotações, lugares e costumes, com a mesma paixão que o conduzia no mundo da ciência.

Culto e apreciador da natureza, Aristides é lembrado por seus contemporâneos como um cientista 'bom de papo': sabia discorrer sobre os mais diversos assuntos com a destreza de um homem de ciência e a simplicidade de um observador atento das coisas do mundo.

\section{$O$ processo de organização}

$\mathrm{O}$ arquivo fotográfico recebeu tratamento que incluiu as etapas de identificação, reprodução, catalogação, indexação, digitalização e acondicionamento.

A identificação das fotografias recuperou informações sobre eventos, pessoas, lugares, datas e autorias. Nesta etapa, a equipe consultou fontes textuais e bibliográficas pertencentes ao acervo da $\mathrm{ABC}$, realizou entrevistas com a viúva Elisabeth Pacheco Leão, com o prof. Hiss Martins Ferreira, seu parceiro por quase meio século, e com o prof. Eduardo Oswaldo Cruz, seu orientando e amigo.

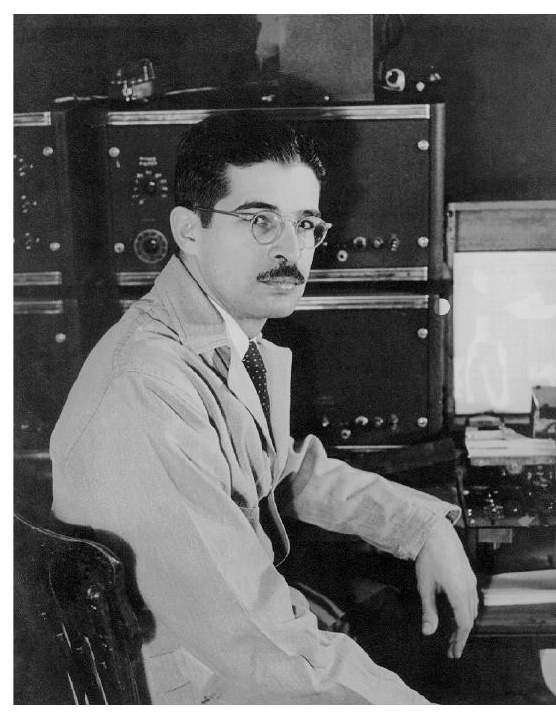

Aristides Azevedo Pacheco Leão por ocasião de seus estudos em Harvard no inicio da década de 1940. Ao fundo, aparece o primeiro eletroencefalógrafo, criado por Grass, antes de sua comercialização. 
Inicialmente, os documentos fotográficos passaram por uma avaliação quanto ao estado de conservação. Em alguns casos, foi necessária a reprodução das imagens, devido à fragilidade do suporte primário e ao precário estado de conservação dos originais.

As imagens fotográficas foram reunidas na série fotografia. Esta série foi dividida em subséries, organizadas cronologicamente, somando 118 dossiês.

ABC (Academia Brasileira de Ciências)

Biofísica (Instituto de Biofísica Carlos Chagas Filho/UFRJ)

CNEN (Conselho Nacional de Energia Nuclear)

Diversos

Eventos

Família

FPROF (formação profissional)

Individual

Terceiros

UnB (Universidade de Brasília)

Unesco (Organização Educacional, Científica e Cultural das Nações Unidas)

Viagens

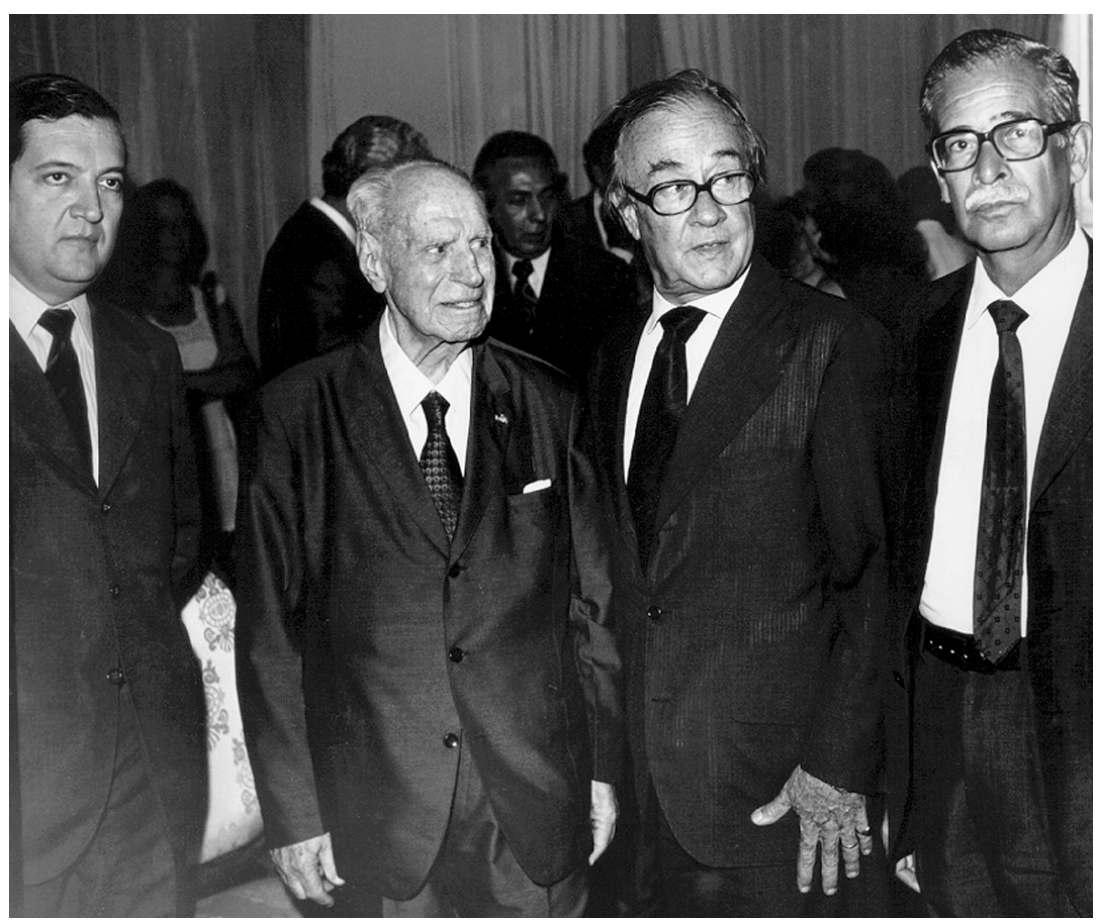

Entrega do prêmio Almirante Álvaro Alberto a Aristides Azevedo Pacheco Leão, conferido pela Secretaria de Ciência e Tecnologia do Estado da Guanabara, durante cerimônia realizada em 1973. Da esquerda para a direita: Francisco de Mello Franco, Álvaro Alberto da Motta e Silva, Carlos Chagas Filho e Aristides Azevedo Pacheco Leão. 
A catalogação dos documentos obedeceu à lógica dos dossiês, respeitando as entradas da área de título, local, data e autoria de imagens, da descrição física e de outros campos dedicados à informação sobre o estado das fotografias.

A indexação do conteúdo das fotografias adotou os termos definidos por um vocabulário de linguagem controlada, de forma a satisfazer a demanda de pesquisadores em história da ciência.

No decorrer do trabalho foi desenvolvido o banco de dados Arquivo Fotográfico Aristides Azevedo Pacheco Leão - visando reunir e divulgar as informações sobre as fotografias. Ao consultar o Arquivo Fotográfico, o pesquisador terá à disposição instrumentos de busca do acervo, que facilitarão o acesso ao conteúdo informativo das imagens fotográficas: índice de títulos, datas, descritores, duplicatas e total de fotografias por dossiês.

Quando da devolução dos originais fotográficos à família, foi feita a seleção das imagens mais significativas da trajetória pessoal e científica do titular, que, posteriormente, foram digitalizadas e inseridas no Arquivo Fotográfico.

$\mathrm{O}$ acondicionamento das fotografias foi planejado dentro das normas específicas para conservação e preservação, com a confecção de material adequado.

O Arquivo Fotográfico poderá ser acessado pelo site da ABC. Outras informações sobre Aristides Azevedo Pacheco Leão e sobre o Projeto Memória podem ser obtidas através de consulta à home page da $\mathrm{ABC}$ : http://www.abc.org.br

\section{Ficha Técnica}

Nome: Aristides Azevedo Pacheco Leão

Sigla:AAPL

Supervisão: Paulo de Góes Filho

Coordenação e execução: Ivanita Raquel Barbosa Velloso e Telma Bonniau

Gitirana

Informatização: Carla Marília dos Santos e Fernando Veríssimo

Responsável pela guarda do acervo: Elisabeth Pacheco Leão

Período de organização: 1998

Período coberto pelo arquivo: final do século XIX até 1994

Espécie: documentos visuais

Quantidade: 552 fotografias e 39 duplicatas 